\title{
Catalogue Communities: Work and Consumption in the UK Catalogue Industry
}

\begin{abstract}
$\underline{\text { Abstract }}$
This paper offers a sociological understanding of the role of catalogue shopping in women's everyday lives. The paper draws on qualitative data generated from interviews with women working at the returns department of the Kays catalogue warehouse in Worcester. During the time of writing, Shop Direct, owners of Kays closed down the historic warehouse in Worcester, effectively bringing over 200 years of Worcester's association with Kays and the catalogue industry to an end, and leading to 500 job losses, including those of the women taking part in the research. Once the largest private employer in Worcester, Kays occupies an important role in local cultural and social identities, and in this paper, I will argue that a sociological account of catalogue shopping is apt and timely given such significant social changes, the recent economic downturn, and social problems that have long been associated with this form of consumption.
\end{abstract}

In addition, the paper will show that to date, much research into catalogue shopping has tended to rest on economic historical accounts of the 'mail order' industry. In contrast, this paper argues that catalogue shopping occupies not only a significant place in the popular cultural imagination surrounding the shopping habits of the working classes (and especially working class women), but has also played a crucial role in women's management of the home, caring for the family, and safeguarding an often limited financial budget. The paper will consider the important role that catalogues have played in offering credit to working class women who may have previously struggled to get this. Finally, it adds to recent attempts to put women's domestic consumption patterns firmly on the academic agenda.

\section{Introduction}

\author{
[Denise is wearing a new leather jacket] \\ Dave: How much was it? \\ Denise: You're just like me dad ... nothing, it's out a catalogue \\ Dave: You've still got to pay for it ain't you? \\ Cheryl: Forty weeks at five pound fifteen
}

(Aherne et al, 1999: 109)

Very little research currently exists which explores the social and cultural trends and processes of the home shopping industry. This is surprising, given the historical and current popularity of shopping from home. Coopey et al (1999) point out that during the 1950s and 1960s, mail order represented Britain's fastest growing retail sector (p.261). Mail order during the 1960s became phenomenally successful with one household in two looking at a mail order catalogue each year, and one in four making a purchase (p.262). Significant changes have occurred in the past 20 years in the mail order industry, and I argue that this reflects broader changes to consumer society. Many of these changes have been technological, such as the recent rise in online shopping and the uses of social network sites such as Facebook for advertising and product placement. The focus of this paper is thus on a very specific moment in the British social history of consumption. The research involved detailed interviews with 
ten employees of the Kays catalogue warehouse in Worcester which closed in 2006, marking a historic end to over one hundred years of trading from Worcester. This is significant not simply because of the impact of job loss but also because it represents a sea change in household consumption patterns. Once a key part of the cultural landscape of British homes, the quick disappearance of the once commonplace and habitual presence of the Kays catalogue illustrates something of the shifts - especially technological shifts - in home shopping.

Certainly, catalogues and the mail order industry have a greater social and cultural significance than is currently given recognition. They also play a particular role in the lives of women consumers. Broadly speaking, catalogues have had three appealing features. Firstly, they are convenient and time saving, secondly, they offer credit deals especially to those who have historically had difficulties in getting credit, and finally, they present a collection of images and 'ideals' which consumers are offered the opportunity to buy into. In this paper, each of these three positions will be explored.

The theoretical argument presented in this paper echoes previous feminist research which has insisted in the importance not only of providing a social and cultural context for the study of women's consumption (see also XXXX), but one which also insists on the importance of 'mapping' intimacies (Sanger and Taylor, 2012) onto everyday lives and in this case, onto consumer experiences. This connects with broader feminist research which has also stressed the importance of providing diverse accounts of intimacies (for example Gabb, 2008; Taylor, 2010). By presenting a sociological account of catalogue shopping, the paper will complement other feminist studies which have explored the role of private, domestic spaces, routines and activities as critical yet often overlooked features of late modernity (see for example, Giles, 2004). I will argue that in catalogues, private dreams and longings are commodified and used to inform visual images which can be translated into consumer goods. Daydreaming might be seen as counter to rationality, but in this paper I will show how catalogues facilitate an interface between daydream and the rational calculations of consumers. I will do this by firstly providing a brief historical account of catalogue shopping which emphasises its particular appeal to working class women consumers. Secondly, I provide an account of how the women's catalogue shopping experiences intersected with their working lives at Kays. Third I consider the particular appeal of catalogue shopping to women on a budget. Finally, I will discuss the uses of catalogues as interface for the disciplining of consumption, fantasy and imagination in everyday life.

\section{'Intimate' at Home Consumption}

One of the particular features of catalogues which makes them such a unique and particular form of consumption, is that they represent an individual, private and crucially, domestic form of consumption. It is clear that one of the most significant impacts that consumption has had on women's lives in the past century, has been the various ways in which public spaces of consumption, first department stores (Carter, 2004) and later shopping malls (Goss, 1993), offered women finally a safe place for the pursuit of pleasure, desire and daydream, or even just the basic freedom to wander, explore, look and socialise without a chaperone. Some feminists have argued that mass consumer culture is one of the worst things that could have happened to women in terms of the unattainable demands of femininity and beauty which consumer capitalism is seen to have so ruthlessly exploited (for example Delphy and Leonard, 1984 and Friedan, 1963). Susan Willis's critique of identity in terms of consumption is a good 
example of this. Arguing that 'falsely constructed notions of control [predominate] over the social reproduction of daily life' (1991: 177), Willis suggests that consumption clouds identity rather than providing any vehicle for true expression. Before catalogue consumption is presented in such a way, this paper will delve deeper into the idea that catalogue shopping, rather than individualised activity, might be more usefully understood by exploring the women's social and self-reflexive accounts of their catalogue consumption.

Importantly, this paper argues that the art of looking, including browsing and comparing, is a fundamental part of consumer culture. It considers within the context of catalogue shopping what the women consumers were looking for, what messages they expected goods to convey and whether or not looking itself is pleasurable. Rosalind Williams, for example, suggests that display was one of the key defining features of the popularity of department stores for women. She argues that:

'What mattered was not the abundance of goods as such, but the ever present vision of such abundance.'

(1982; p.58)

The small amount of available research has tended to focus on market trends in catalogue shopping. This sheds light on the key characteristics of home shopping. For example, a Mintel survey of home shopping conducted in 2003, found that mail order shopping still dominates the UK home shopping market, and that the traditional consumer base of women aged 35-55 years remains static (2003: 6). The survey also found that home shopping retains a constant, indeed slightly increasing share of all retail sales. Between 2000 and 2002 home shopping accounted for a $7.4 \%$ and $9.5 \%$ share of all retail sales respectively (p.10). However, the Mintel report usefully points out the need to distinguish between different types of home shopping, in order to gain as full a picture as possible of the home shopping market. For example, although general mail order continues to rise, its market position is threatened by a dramatic increase in e-commerce (p.12), by increased availability of interest-free credit and by a declining interest in 'big book' catalogues as opposed to 'tailored' products (p.55). Thus:

"Big book" agency catalogues featuring a range of different items, from clothes to household appliances, are losing popularity and sales, while "direct" catalogues that cater for niche markets ... are succeeding ... Catalogues that offer a multitude of different products are considered "down market", and "old fashioned", whereas direct / niche catalogues are developing their appeal.'

(Mintel, 2003: p.76)

This echoes Alison Clarke's argument that in many middle class households, mail order is seen to be 'inappropriate' or not 'respectable' (1998: 90). Underpinning the theoretical framework of this paper is a wish to reposition catalogue shopping within the context of gender and class. As Clarke commented in her discussion on forms of home consumption, catalogues are central to the 'dynamic of class, style and knowledge in consumption activity' (p.73). It is certainly the case that catalogues and catalogue shopping occupy a significant place in the popular British cultural imagination and have a close association with gender and class as the introductory quote from the popular British sitcom The Royle Family illustrates. 
For the purposes of this paper, I argue that it is useful and appropriate to explore in detail the complexities of everyday life, and especially domestic consumption practices (see also Ilmonen, 2001). One of the broader aims of the project was to readdress the existing theoretical imbalance of previous research into the main order industry which has tended to produce general information including industry trends. Whilst this has identified some interesting historical shifts in the mail order industry for example, the existing research has also overlooked consumer experience, in particular the diverse, everyday and intimate economies of consumption. I consider that for the women of this research, catalogue shopping represented a space where various intersections including class, gender, work and motherhood are mapped.

It is certainly the case that very little is currently known about women's everyday routines of consumption, with some notable exceptions (Casey and Martens, 2007; Giles, 2004; Silva 2004 etc.). This paper addresses this dearth by offering an account of a group of women's everyday experiences of catalogue shopping, and moreover their long-term employment within the catalogue industry. The account that follows is one which provides an analysis of the everyday intersections between consumption and work / employment and looks to see how catalogue shopping for the women taking part in the research represented a key part of their shared identities, histories and lives. By examining the complexities and contradictions of home shopping, it is hoped that I will be able to assess the extent to which poverty and wealth operate within household consumption patterns (see also Clarke, 1998 and Paugh, 2004).

\section{$\underline{\text { Catalogue Communities }}$}

It would be impossible to produce any truthful analysis of the women's experiences of catalogue consumption without first recognising the importance of the fact that the women taking part in this research also worked in the catalogue industry. According to the Mintel report, there is a constant and on-going trend for women outnumbering men working in mail order retail, and a trend for part-time women workers (2003: 19). Additionally, the Mintel report calculates a lower than average income of those working in the mail order industry (p.20). In this sense, the women had an affiliation with the brand which transcended their position as consumers. As employees of the catalogue, it would have been unwise to attempt to dislocate their experiences as customers from their status as employees. Indeed, throughout the interviews, the women always identified themselves both as employees and as consumers. The research provided an excellent opportunity to examine in more detail the notion of catalogue 'communities', or more precisely, the communal experiences of consumption which, again, is broadly absent from much of the sociological literature on consumption (see also Glennie and Thrift, 1996).

It seemed for the women taking part in this research that neither definition of everyday life is ideal, and that there was no easy separation from the state, their working lives and their private lives and familial ties. The women who took part in this research had seen considerable change over the years of working at Kays, some welcomed and some resisted, including dramatic technological changes. Rose felt that the technological changes that she had experienced over her 30 years of working for Kays had damaged the experience of working life: 
'I still feel like I am in training! [...] One thing I can never get my head around is that before automation - going back fifteen years - our team was a lot greater than it was now. Lots of business systems have been brought in for all sorts of different reasons and I tend to think the atmosphere is more cold now.'

To an extent, the work was a way of life, part of a community and lifestyle. It could be argued that Kays represented one of the last bastions of local retail with fully unionised work. Griffin's classic study of young working class women experiencing the transition from school to work seems remarkably prophetic in the context of this research (1984). In her research of young women working on factory assembly lines, in shops and in offices, Griffin concluded over twenty years ago that these jobs remained predominantly 'female' jobs, with poor pay and conditions, low status, minimum training and promotion prospects and with low levels of union membership due to employer opposition (p.37). She concluded also that women workers enjoyed the company of other women at work, and that domestic commitments had largely shaped their decision to work and their choice of job (ibid). My point here is that the work was more than simply 'work' to the extent that the women who worked there had developed an affiliation with the company and saw it as part not only of their community, but was also entwined with their identities. Often, the women spoke with nostalgia about their work. Rose reminisced of a time when she felt that life at Kays was comparable to family life:

'The environment and the culture has changed an awful lot - it was more like a family - an extension of your family, years ago, which I think is quite sad. We haven't got that now ... and whether it is because we have expanded ... it was nothing like all those years ago. I don't know what it is really, but family, you had people who would look out for you - we haven't got that so much now.'

In this research it was impossible to separate consumption from work. Indeed, the women's individual stories, histories and biographies of work and employment at Kays were always necessarily entwined with broader discussions of consumption. This is in part evidenced by the buoyancy of the Kays Heritage website which includes a wealth of information about the company and places emphasis on the role of Kays in the local history of Worcester. For the women taking part in this research, their work was never just that; rather, their employment was part of their local community and historical identity. Many had worked at Kays for over 30 years, and for most, it was the first and only job that they had ever had as Rose described:

'My sister was driving and I was in the car and so was my Nan. We were going shopping in Worcester and I knew somebody that had started here. I just came in this one Saturday morning, came in through security as it was then and asked if I could see somebody. There was Mrs. Hughes one of the managers and it was just like that, no "what makes you think or why do you want to work here?" I just thought well why not, it's as good a place as any. They took me on and said I could start on that Monday which I did. Needless to say, I just wanted to earn money. I have to this day still got my first wage slip. I can't remember what exactly the pay came in at, but on the back of it 
I'd written what I had spent my money on ... I think I bought an LP, something or other for sixpence. I had given my mum some money.'

(Rose, employee at Kays for 30 years)

I have cited Rose's biography of her career at Kays at length because it encapsulates a number of key points that this paper seeks to make. Rose merges her discussion of her employment at Kays with other important points about her life. It shows how employment is triggered by personal relationships and demonstrates the relationship between work and consumption. Indeed, working at Kays also combined employment with personal connections and friendships:

'I left school when I was 15 and I mean you couldn't get a job until you were 16 - I couldn't work. I was 16 in the August then I came here in October 'cause it used to be like temporary ... October 'til the December "cause they used to lay you off at Christmas ... then I came back in the January and that was January $1978 \ldots$ they made me permanent then. It was the day after my $16^{\text {th }}$ birthday. Me mum said "you better get yourself a job" and I went down the careers office and they said OK come for the interview and the girl what lived round the back from me, she was working here as well and she said - "oh it's all right, come along with us".'

(Jean, worked at Kays for 26 years)

Many of the women recognised the changing and risky position of the catalogue industry and voiced these concerns throughout the interviews. I have already mentioned the ways in which Kays occupies an important part of the collective conscience and imagination of the community of Worcester. This nostalgia combined with a sense of loyalty and feeling of shared ownership of the company meant that Kays was integrated into women's lives and experiences in a way that working in other parts of the retail industry was not. In particular, there was a strong element of frustration and defensiveness that the company and its products might be perceived to be cheap or 'budget'.

\section{Managing and Consuming on a Budget}

The idea that there is no easy separation between home / domestic space and the demands and constraints of public life had particular reticence for the women of this research for whom the decision to work, and their various consumption decisions were interwoven with their everyday routines and experiences of domestic life. To a certain extent, this is already demonstrated by existing research such as Larson (1992) which shows how in contemporary capitalist consumer economies, intimate details of private lives become public knowledge, increasingly shared amongst companies to enable targeted direct mail outs to individuals. Today, supermarket reward cards habitually collect information about shopping habits of individuals as they spend and use this to tailor mail outs to consumers and the Internet offers infinite possibilities for retail companies to track consumers' spending behaviour and to directly target marketing material via social networking sites for example. Delphy in an early related piece of work, argues that much sociological research alludes to consumption and its role in the household, but fails to adequately describe and explore the positions of various 
different individuals which form the household. In this sense, it is not enough to collect simple statistics on what women consume, but instead, more complex understandings of how women consume - in this case, via the pages of catalogues - and how their decisions to consume in particular ways are bound up with their position in the family. In particular, Delphy points out that as money managers of the home, women typically 'find themselves confronting situations for which no instructions exist' (1984: 50-1) and furthermore, that money management and credit are learned and taught techniques (see also Braudel, 1981).

I argue that for the women of this research, shopping using catalogues was only partly pleasurable - often it was more to do with necessity, routine and budgeting. This concurs with Pugh's (2004) finding that in families where money is scarce, there exists a culture of restraint over money that is not present in upper and middle class households (p.244). speaking of the 'symbolic oppression of the flawed consumer' and the 'flawed mother', Pugh suggests that families frequently resort to the passive language of good and bad luck which can often make or break a household budget (p.246). Similarly, credit schemes had become an important part of the discussions of household budgeters. The women talked about both their relief that access to credit sometimes offered, but also a recognition that using credit might be perceived as a problematic or 'flawed' form of consumption.

In this research, credit and debt are often mentioned as a key means through which shopping and household budgeting takes place. The availability of credit was cited as one key factor influencing the women's decisions to use catalogues throughout their lives as Kath remarked:

'I looked at things [in catalogues] when the children were smallI think then you had a lot more people with no credit cards. We didn't have credit cards when my kids were small. We were struggling then and you could order things and then it was a small percentage every week. With so many more people ordering from the catalogue there was such a variety. An aunty of mine ordered a wedding dress.'

As the quote above illustrates, until fairly recently, catalogues were one of the only means for working class women of gaining credit, and moreover, credit which has a $0 \%$ interest rate with small, affordable and flexible re-payments. Importantly, gaining credit through catalogues was designed to appeal to 'respectable' working class women for whom 'being in debt' or consuming 'on the never-never' was seen as a sign of losing control of the household budget. In contrast, the credit system offered by catalogues, and the system of collections of repayments by local 'agents' offered a friendly and acceptable way of getting credit. As Coopey et al. (1999) point out:

'The local agency system dovetailed neatly with credit provision; "Joan from down the street" and "Aunty Kathleen" were extremely effective credit policewomen, ensuring that bad debt were minimized. Only the toughest of customers would delay payments to an agent that they were likely to encounter every day.' 
The women's wariness of credit and debt was clear throughout the interviews, although interestingly there was far less fear of catalogue credit schemes than credit and store cards. Kath, for example, had very strong opposition to store cards with high interest rates:

'They advertise all these credit cards with such high interest. People say, "Oh you can just get a credit card and go down the shops". But I didn't realise how much interest the shop card puts on. You go into a shop and they say you can have a special deal if you open an account today - you can have $£ 5$ or $£ 10$ off your shopping. But you are going to put it on your credit card! And I think, "no", very tempted but if I can't afford to pay for it, I don't really want it.'

Chris also expressed a fear of credit card debt and was keen to distance herself from it despite using catalogue credit schemes:

'It is easy and youngsters are so vulnerable with credit - they do not realise - I mean as old as I am I don't have a credit card - I have the Switch but I will not have a credit - its so easy to say "oooh I like that"

Credit and debt, though and attitudes towards this were always off-set against criticisms of excessive debt and 'dangerous' consumption. Perhaps using the credit systems of catalogues is seen as 'friendly', 'accessible' and easy to use, and is not time-consuming. Women were acutely aware that the $0 \%$ credit charge is misleading and defended themselves against accusations of being 'irresponsible' spenders. On the contrary, their consumption was responsible, safe and defended the stability of their domestic lives and rituals. Lynne distinguishes herself from those who use credit in an 'inappropriate' way by demonstrating her own understanding of the conditions in which credit is offered:

'They push up the date in January - order now, pay September, so a lot of people go mad - "oh I don't have to pay this 'til September" ... I think that has something to do with it. I mean it's great having something for nine months and not paying for it.'

The women of this study were neither time, nor cash rich. This meant that catalogues offered a dual appeal of offering easy access to credit, combined with a method of consumption which could easily complement work and domestic routines. O'Sullivan and Gershuny's (2004) study usefully points to a lack of time available both for consumption and leisure as one of the key defining features of contemporary capitalist consumer society. They point out the limitations of Veblen's early account of conspicuous consumption, arguing that Veblen's leisure class required time for consumption, which is curtailed amongst the cash rich in contemporary society. I argue that catalogues offer a space for consumption for the time poor, but also, uniquely, the cash poor.

\section{Catalogue Shopping and Women's Everyday Domestic Routines}


I have argued above that consumption for many women is not separated out from work and employment. In the discussion above, it was pointed out that retail / consumption is a key career choice for many working class women. However, for women consumers, the act of consumption itself is also closely entwined with the unpaid labour of the home. Appadurai (1996) argues that if consumption is to be re-presented as a form of work, it is appropriate to move beyond accounts of the 'Consumer Revolution' and instead, to reconfigure debates about the nature of consumption to the 'revolution of consumption' (p.82). This idea seems particularly apt for this research. The UK mail order industry is in a constant state of flux and change as 'new revolutions' in consumption step forward to replace old ones. Coopey et al (2005) for example, point to internet shopping as the latest revolution in consumption patterns. This does not mean that the mail order industry is dying, only that significant structural changes are occurring which directly impact upon women's lives, notably the closure of the Kays warehouses in Worcester. However, when Appadurai writes of the 'revolution of consumption', he means more than simply changes to the broad ways in which individuals consume, i.e. using a catalogue, ordering goods on-line, browsing etc. Moreover, he pin-points changes in the way time is managed and increasingly becomes a commodity itself in contemporary capitalist, consumer society. In other words, part of the revolution of consumption lies in the disciplining of consumption. As we shall see, this has particular pertinence when contextualising consumption within working class women's everyday lives. Appadurai writes:

\begin{abstract}
'... the desire for new bundles of commodities [...] learning how to navigate the open-ended temporal; flows of consumer credit and purchase in a landscape where nostalgia has become divorced from memory, involve new forms of labour: the labour of reading ever-shifting fashion messages, the labour of debt servicing, the labour of learning how best to manage newly complex domestic finances, and the labour of acquiring knowledge in the complexities of money management.'
\end{abstract}

(pp. 82-83)

I will return to Appadurai's themes of the disciplining of fantasy and the imagination later on in this paper, but for now, I want to spend more time considering his views on consumption as it is interwoven with the various demands on women's lives. The interviews conducted for this research were scattered with references to family life and it became clear that the decision to work at Kays was closely associated with the demands and complexities of everyday life. Indeed, the work was not simply seen as a means of earning money, rather it held an especially important position in terms of household budgeting and the women's domestic consumption practices. To begin with, for the women workers, the staff discount was almost as important as their pay. Lynne, who was quoted earlier, for example, suggested that agreements about staff discount often occurred at the expense of pay increases. Staff discount certainly represented an important part of the women's livelihood and a crucial part of the household budget of the family. For example, Lynne points to the importance of her staff discount for her whole family:

'My sister wanted a three-piece suite when she moved and it worked out she was just paying for the sofa. You know she was getting the two armchairs for nothing really.' 
The work also complemented family life in other ways. In particular, it fitted in with often packed and hectic time schedules and being 'available' for children and the family as Kath, who had worked in the returns department for 19 years remarked:

'I started 19 years ago - I came in previously before that as a packer - the kids were at school and it just sort of fitted in. You could finish when you wanted - that was the ideal place to work. Then I came back on a second contract and they had just opened this call store and they were doing trials with the computer and that, so they took on anyone who had brains or who could add up.'

For the women taking part in this research, the necessity of paid work was always combined with the contradictory demands of managing a tight budget and being responsible for the family. Enjoying the job was an added bonus. This supports a whole range of other time budget studies that have demonstrated time to be a gendered concept and one where, for many women, the temporal rhythms of everyday life are always structured around responsibilities to others (for example, Hochschild, 1997; Southerton, 2003; Sullivan, 1997). Kremer-Sadlik and Paugh (2007) have also suggested that in contemporary capitalist society where time is at a premium, it is often necessary to search for 'alternative' ways of finding pleasure and quality time for self and family. It was interesting to listen to the women's discussions of how they actually used catalogues; how they read them and how they budgeted their time to fit catalogue shopping into their everyday routines. Although catalogue shopping requires actual time dedicated to this activity, it can, to a certain extent take place alongside other demands of the day. Whereas 'going shopping' requires dedicated time, and can frequently lead to 'wasted time' (see also Goss, 1993), the women of this research often reached for the catalogue when they had 'a spare five minutes', or when circumstances demanded it. For example, 'he'll say, "Mum, I need some new trainers" and I'll just get the catalogue and have a look'. However, big purchases were never a simple choice. For many of the women, using catalogues involves a complex decision of budgeting off-set against availability and choice in catalogues. Certainly, as a form of household budgeting and management, catalogue shopping, although relatively time saving and convenient, was never straightforward especially for women on a low income (see also Charles and Kerr, 1988; DeVault, 1991; Casey and Martens, 2006 for other studies of household budgeting in low-income families). Kath succinctly demonstrates the complexities of catalogue shopping:

'I like to sit, I think because I've got such a busy life, I need to fit it in and look through the catalogue at leisure. I don't want to walk around town, I don't want to go to a meeting or a social gathering. I can sit and look through the catalogue if I want something. You want something you can browse through. I have got Next [catalogue] and I go on the Internet as well. I struggle to get on but I'm not bothered as long as I get good value. I wanted a dishwasher, I looked through the catalogue, I worked out I could get a discount on it but it didn't do the things I wanted. It was a bad choice so then I went out and had a look round Apollo, Curry's. I went to them all - got fed up looking but there was only so much in the catalogue. So it's choice at 
the end of the day. I look in the catalogue first but if I'm not happy I will look elsewhere.'

The decline in the mail order industry tells us something about how budget shopping overall has changed. Whilst once catalogues were seen as 'department stores in a book' (Mills, 2003: 35), now big supermarket chains are seen as the physical equivalent of catalogues. Walking around a large British supermarket, can offer a sense of being inside a catalogue warehouse, as Rose commented:

'If you think about it, in supermarkets nowadays you can get absolutely anything ... if you go to the big Asdas for example, you have to travel to get there but you can get anything from a pair of socks to a fridge freezer ... If you look at what has come into the country over these last few years - you have shops like Walmart, Matalan, Primark - all these sorts of things, and to be fair, they have quality clothing. Yes, you have to pay cash for it and there are people who look for the mail order because they haven't got that initial outlay of paying the whole thing.'

\section{Spaces for Browsing and Dreaming}

As the above discussion shows, the use of the catalogue is very convenient and fits in with often very hectic time schedules. But, is catalogue shopping purely utilitarian and convenience? What about the pleasures associated with catalogue shopping? I want to return now to Appadurai's ideas of the disciplining of the imagination, and especially his work on nostalgia and fantasy, which I would argue, has particular significance in understanding the women's experiences of mail order shopping. It is especially useful to consider how the women differentiated their private, domestic catalogue shopping from their experiences of shopping in public. Kath for example, distinguishes between shopping for 'leisure' and shopping using catalogues. She recognises the pleasures of shopping but contrasts this with the usefulness of catalogues as a means of comparing prices:

'I'm not old fashioned but I would like something that would suit me and I don't want to go into town all the time. Judging from people around me like me nieces, they like to go into town, but it's not part of just stopping to buy an outfit, it's a social gathering. You can get stuff in town but again for people who are on a lower income if you have a catalogue or three or four, you can compare the prices or compare the products.'

For some of the women, catalogues were an opportunity to browse and to 'get ideas' for consumption. Lynne for example, uses catalogues as a form of pleasurable and relaxing window shopping or 'browsing':

'Sometimes you have an idea of what you know you want to order but other times you think "oh, I'll just sit down with the catalogue for five minutes and you look at the catalogue for a few minutes and go "oh I don't remember seeing that first time round", probably because you were just flicking through it. You 
actually have got time to sit down and look at it in a different light.'

For women who shop on a budget, a key challenge to the catalogue industry is the rise, as mentioned earlier, of cheap 'bargain' shops. Clarke (1998) points out that the late 1990s saw an increasing number of shops selling a broad range of discount goods. These shops increasingly offer bargains, functionality and convenience but interestingly, they do so whilst offering no elaborate display or presentation of goods. I argued in the introduction to this paper that catalogues appeal to working class women because they offer bargains, credit and a space to daydream, imagine and fantasise about consumer goods. Catalogues are different because they offer a space to daydream in the same way, perhaps that the first department stores offered fantastical and opulent displays in a public space, which, uniquely was accessible to unaccompanied middle class women (see Carter, 1984). However, it was through catalogues that working class women were provided with access to such a space. Catalogues have played an important interface through which working class women have been able to read various messages and to dream. As Clarke also points out, catalogues equip working class women with the opportunity for a fantasy and imaginative shopping experience - to daydream, browse, choose and purchase - in a consumption space which avoids the stress of shopping in expensive shops on a limited income (see also Clarke, 1998: 93). For example, the use of celebrities to model clothes and the introduction of 'new' innovations of consumerism, for example the 1976 / 77 Kays catalogue included the microwave oven; 'an entirely new concept in home cooking'. I argue that although catalogues may address 'needs' more directly than other types of consumption such as shopping malls for example, they do so whilst also offering spaces to daydream, imagine and fantasise about the impact of goods both on self and on the family.

\section{$\underline{\text { Conclusion }}$}

Recent years have seen a growing interest in what I have called 'intimate' experiences of consumption and articles on this topic are increasingly commonplace in sociology journals. One of the great benefits of this research has been a renewed interest in 'moments' of consumption and in particular how these moments are rooted in individual biographies as well as in historically, culturally and socially significant events and structures. Despite this focus however, catalogue shopping continues to be almost entirely overlooked by consumption scholars, which seems particularly surprising given the huge proliferation of online, at home shopping in recent years. Thus, it is hoped that one of the outcomes of this paper might be further research into the technological advances of at home consumption. Furthermore, as I have shown in this paper, catalogue shopping has long been a value laden form of consumption and one which plays a particularly important role in understanding rapidly changing consumption patterns particularly for working class women in the latter part of the twentieth century.

In this paper then, I have tried to represent catalogue shopping among a group of women who worked in the catalogue shopping industry and to position their catalogue consumption within a complex spectrum of identity practices. Catalogues are thus one way of realising some of the limitations of conventional dichotomies of modernity. I have shown in this paper how for a group of women who had worked for many years at a household name catalogue company, their experiences of consumption were entwined with their broader experiences of life and specifically of the particular and intersecting binds of class and gender. The paper 
demonstrates how class and gender intersect with experiences of consumption and how the emotional work of consumption is entwined with intimate and work life.

\section{$\underline{\text { References }}$}

Aherne, C., Cash, C., \& Normal, H. (1999). The Royle Family: The Scripts. London: Granada Media.

Appadurai, A. (1996). Modernity at Large: Cultural Dimensions of Globlization . Minneapolis: Minnesota Press.

Braudel, F. (1981) The Structures of Everyday Life: The Limits of the Possible. London: Collins

Carter, E. (1984). Alice in the Consumer Wonderland. In A. McRobbie (Ed.), Gender and Generation. London: Macmillan.

Casey, E., \& Martens, L. (2006). Gender and Consumption: Domestic Cultures and the Commercialisation of Everyday Life. Hampshire: Ashgate.

Charles, N., \& Kerr, M. (1988). Women, Food and Families. Manchester: Manchester University Press.

Clarke, A. (1998). Window Shopping at Home: Classifieds, Catalogues and New Consumer Skills. In D. Miller (Ed.), Material Cultures: Why Some Things Matter. London: UCL Press.

Coopey, R., O'Connell, S., \& Porter, D. (1999). Mail Order in the United Kingdom: How Mail Order Competed with Other Forms of Retailing. The International Review of Retail, Distribution and Consumer Research, 9, 261-273.

Coopey, R. (2005). Mail Order Retailing in Britain: A Business and Social History. Oxford: Oxford University Press.

Cunnison, S. (1983). Participation in Local Union Organisation. School Meals Staff: A Case Study. In E. Gamarnikow, D. Morgan, J. Purvis \& D. Taylorson (Eds.), Gender, Class and Work. Aldershot: Gower Publishing.

DeVault, M. L. (1991). Feeding the Family: The Social Organization of Caring as Gendered Work. Chicago: University of Chicago Press.

Delphy, C. and Leonard, D. (1984) Close to Home: A Materialist Analysis of Women's Oppression. MA: University of Massachusetts Press

Friedan, B. (1963) The Feminine Mystique. New York: Norton \& Co.

Gabb, J. (2008) Researching Intimacy in Families. Basingstoke: Palgrave

Giles, J. (2004). The Parlour and the Suburb: Domestic Identities, Class, Femininity and Modernity. Oxford: Berg.

Goss, J. (1993). The Magic of the Mall: An Analysis of Form, Function and Meaning in the Contemporary Retail Built Environment. Annals of the Association of American Geographers, 83, 18-47.

Griffin, C. (1984). The Transition from School to the Labour Market for Young Working Class Women. Birmingham: Centre for Contemporary Cultural Studies.

Hochschild, A. R. (1997). The Time Bind: When Home Becomes Work and Work Becomes Home. New York: Henry Holt.

Ilmonen, K. (2001). Sociology, Consumption and Routine. In J. Gronow \& A. Warde (Eds.), Ordinary Consumption. London: Routledge.

Kremer-Sadlik, T. and Paugh, A. (2007) Everyday Moments: Finding "Quality Time” in American Working Families. Time \& Society. 16 (2/3), 287-308

Larson, E. (1992) The Naked Consumer: How Our Private Lives Became Public Commodities. New York: Henry Holt 
Lawler, S. (2005). Disgusted Subjects: The Making of Middle-Class Identities. Sociological Review, 53, 429-446.

Mackay, H. (1997) Consumption and Everyday Life. London: Sage.

Mills, B. (2003). Kays of Worcester: A Pictorial History of the Mail Order Company. Kempsey: Flag.

Mintel (2003). Home Shopping. London: Key Note Ltd.

Paugh, A.J. (2004) Windfall Child Rearing: Low-Income Care and Consumption. In Journal of Consumer Culture. 4 (2), 229-249

Radner, H. (1995). Shopping Around: Feminine Culture and the Pursuit of Pleasure. London: Routledge.

Roberts, K. (2005) The Cultural Turn in Leisure and Tourism Studies. In A. Chandra and D. Nigan (Eds.) Tourism, Environment and Ecology. New Delhi: Shree Publishers

Sanger, T. and Taylor, Y. (2012) (eds.) Mapping Intimacies: Relations, Exchanges, Affects. Basingstoke: Palgrave

Sennett, R., \& Cobb, J. (1972). The Hidden Injuries of Class. London: Cambridge University Press.

Silva, E., \& Bennett, T. (2004). Contemporary Culture and Everyday Life. Durham: Sociologypress.

Skeggs, B. (1997). Formations of Class and Gender. London: Sage.

- (2004). Class, Self, Culture. London: Routledge.

Southerton, D. (2003). "Squeezing Time": Allocating Practices, Co-ordinating Networks and Scheduling Society. Time \& Society, 12 (1), 5-25.

Sullivan, O. (1997). Time Waits for no (Wo)man: An Investigation of the Gendered Experience of Domestic Time. Sociology, 31, 221-39.

Sullivan, O. and Gershuny, J. (2004) Inconspicuous Consumption: Work Rich, Time-Poor in the Liberal Market Economy. Journal of Consumer Culture, 4(1), 79-100

Taylor, S. (2002) Attacking the Cultural Turn: Misrepresentations of the Service Encounter. In Sociological Research Online, 7 (1) <http://www.socresonline.org.uk/7/1/taylor.html>

Taylor, Y. (2010) (ed.) Classed Intersections: Spaces, Selves, Knowledges. Hampshire: Ashgate

Williams, R. (1982) Dream Worlds, Mass Consumption in Late Nineteenth-Century France. Berkeley: University of California Press 